\title{
ANGKUTAN MASSAL SEBAGAI ALTERNATIF MENGATASI PERMASALAHAN KEMACETAN LALU LINTAS METROPOLITAN SARBAGITA
}

\author{
Hendrialdi ${ }^{1}$, Ni Wayan Putu Sueni ${ }^{1}$, Ahmad Soimun ${ }^{2}$, Anggun Prima Gilang Rupaka ${ }^{2 *}$ \\ ${ }^{1}$ Manajemen Transportasi Jalan, Politeknik Transportasi Darat Bali, Jl. Cempaka Putih, Desa Samsam, \\ Kec.Kerambitan, Kab. Tabanan - Bali, Indonesia 80582 \\ ${ }^{2}$ Manajemen Logistik, Politeknik Transportasi Darat Bali, Jl. Cempaka Putih, Desa Samsam, Kec.Kerambitan, \\ Kab. Tabanan - Bali, Indonesia 80582 \\ *gilang@poltradabali.ac.id
}

\begin{abstract}
ABSTRAK
Peningkatan kebutuhan akan jasa angkutan bagi mobilitas orang serta barang seiring meningkatkan perkembangan pendudukan dan pengembangan pemukiman yang semakin luas terutama di kota-kota besar. Tujuan dari penelitian ini adalah mengetahui kualitas moda angkutan umum apa saja yang ada di kawasan metropolitan SARBAGITA, mengetahui seberapa efektif dan efisien angkutan umum yang sudah ada, mengetahui Konsep pengembangan angkutan umum, untuk meningkatkan kemauan masyarakat menggunakan angkutan umum guna mengurangi kemacetan lalu lintas di di kawasan metropolitan SARBAGITA, dan mengetahui fasilitas penunjang dalam menarik masyarakat untuk menggunakan angkutan umum di kawasan metropolitan SARBAGITA. Peminat masyarakat menggunakan angkutan umum masih sangat rendah hal ini dikarenakan kurang efektifnya angkutan umum yang sudah ada seperti terbatasnya operasi yang ada. Dari hasil wawancara sebanyak 130 responden dan Dinas Perhubungan Kawasan kota Metropolitan SARBAGITA pengembangan angkutan massal sudah direncanakan dengan baik dan sudah mulai beroperasi seperti bus transabagita dan Teman Bus. Dari segi fasilitas penunjang transportasi Kawasan sudah cukup baik seperti keberadaan terminal, letak halte dan aksesibilitas angkutan kota. Untuk meningkatkan kemauan masyarakat dalam menggunakan moda angkutan massal harus diperhatikan rute angkutan massal tersebut mengingat Kawasan SARBAGITA merupakan penyokong pariwisata provinsi Bali.
\end{abstract}

Kata kunci: angkutan massal; kemacetan; sarbagita

\section{MASS TRANSPORT AS AN ALTERNATIVE TO OVERCOME TRAFFIC TRAFFIC PROBLEMS OF SARBAGITA METROPOLITAN}

\begin{abstract}
The increasing need for transportation services for the mobility of people and goods is in line with the development of occupation and the development of increasingly wider settlements, especially in big cities. The purpose of this study is to determine the quality of any public transportation modes in the SARBAGITA metropolitan area, to know how effective and efficient existing public transportation is, to know the concept of developing public transportation, to increase the public's willingness to use public transportation to reduce traffic congestion in the area. the SARBAGITA metropolitan area, and knowing the supporting facilities in attracting the public to use public transportation in the SARBAGITA metropolitan area. Public interest in using public transportation is still very low, this is due to the ineffectiveness of existing public transportation such as the limited existing operations. From the results of the interviews, as many as 130 respondents and the SARBAGITA Metropolitan City Transportation Agency, the development of mass transportation has been well planned and has started operating, such as Transabagita bus service and Teman Bus. In terms of transportation support facilities, the area is quite good, such as the existence of a terminal, location of bus stops and accessibility of city transportation. To increase the public's willingness to use mass transportation modes, the mass transportation route must be considered, considering that the SARBAGITA area is a supporter of tourism in the province of Bali.
\end{abstract}

Keywords: public transport; sarbagita; traffic 


\section{PENDAHULUAN}

Peranan transportasi dalam perkembangan sangat penting dalam menunjang kegiatan perekonomian. Kebutuhan moda transportasi yang sangat memadai sangat dibutuhkan oleh masyarakat. Pentingnya transportasi tersebut tercermin pada semakin meningkatnya kebutuhan akan jasa angkutan bagi mobilitas orang serta barang sebagai akibat meningkatnya perkembangan penduduk dan pengembangan pemukiman yang semakin luas terutama di kotakota besar.

Kota Denpasar merupakan ibukota Provinsi Bali yang merupakan kota menurut BPS Kota Denpasar mencatat jumlah penduduk pada tahun 2018 sekitar 930.600 jiwa. Hal ini menunjakan Kota Denpasar juga disokong oleh beberapa daerah penyokongnya di antaranya Kabupaten Badung, Kabupaten Gianyar, dan Kabupaten Tabanan. Sehingga pemerintah pusat dalam rancangan pengembangan wilayah telah menetapkan 6 kawasan metropolitan di luar pulau jawa yang akan dikembangan salah satunya di Provinsi Bali yaitu kawasan metropolitan SARBAGITA.

Faktor-faktor lain pun perlu diperhatikan dalam perancangan angkutan umum suatu kota harus di ketahui dahulu angkutan umum yang sudah ada di daerah kawasan tersebut. Kawasan SARBAGITA sekarang ini sudah ada bus rapit transit Sarbagita yang merupakan angkutan umum yang dikeluarkan oleh Dinas Perhubungan Provinsi Bali. Penelitian ini bertujuan untuk mengetahui: (1) Jenis dan jumlah angkutan umum di kawasan Sarbagita, dan (2) Efektivitas dan efisiensi angkutan massal di kawasan Sarbagita.

\section{METODE}

Pengumpulan data dilakukan dengan studi survey langsung, wawancara, dan penyebaran kuesioner kepada masyarakat untuk mengetahui efektivitas dan efisiensi angkutan umum sekaligus melihat tingkat keinginan masyarakat dalam menggunakan angkutan umum. Selain itu dilakukan wawancara pada stakeholder terkait yaitu Dinas Perhubungan daerah setempat di kawasan Sarbagita untuk mengetahui jenis dan jumlah angkutan umum. Lokasi penelitian dilakukan di kawasan Metropolitan Sarbagita.

\section{HASIL DAN PEMBAHASAN}

Kawasan Metropolitan Sarbagita telah ditetapkan berdasarkan Peraturan Presiden No. 45 Tahun 2011 tentang Rencana Tata Ruang Kawasan Perkotaan Denpasar, Badung, Gianyar, dan Tabanan (Sarbagita). Perpres tersebut mengatur mengenai peran dan fungsi Rencana Tata Ruang Kawasan Perkotaan Sarbagita, cakupan, tujuan, kebijakan, strategi, rencana struktur ruang, rencana pola ruang, arahan pemanfaatan ruang, dan arahan pengendalian pemanfaatan ruang, serta peran masyarakat dalam penataan ruang Kawasan Perkotaan Sarbagita. Selain itu, Perpres juga memuat Peta Rencana Struktur Ruang Kawasan Perkotaan Sarbagita, Peta Rencana Pola Ruang Kawasan Perkotaan Sarbagita, dan Indikasi Program Utama Lima Tahunan Arahan Pemanfaatan Ruang Kawasan Perkotaan Sarbagita. Data dari Dinas Perhubungan Provinsi Bali didapatkan data pada tabel 1.

Survey dilakukan pada kawasan kota metropolitan SARBAGITA untuk mengetahui tingkat pengguna angkutan umum dalam melakukan aktifitasnya sehari hari. Sebelum melakukan survey diperlukan data primer jumlah pendudukan Kawasan SARBAGITA yang didapatkan dari BPS setiap kabupaten kota. Survey dilakukan pada hari kerja Dan juga pada hari libur untuk mengetahui tipe karakter masyarakat dalam menggunakan moda untuk bepergian. Survey wawancara dilakukan kurang lebih 1,5 bulan Sepetmber - oktober untuk mendapatkan jumlah responden yang sesuai dengan tujuan dan maksud penelitian. 
Tabel 1.

Jumlah Armada Angkutan Umum AKDP menurut Trayek Provinsi Bali

\begin{tabular}{llll}
\hline No & Trayek & Jumlah Armada & Panjang Trayek \\
\hline 1 & Singaraja - Mengwi & 68 unit & $101 \mathrm{~km}$ \\
\hline 2 & Mengwi - Gilimanuk & 69 unit & $116 \mathrm{~km}$ \\
\hline 3 & Tegal - Kuta - Tuban & 19 unit & $18 \mathrm{~km}$ \\
\hline 4 & BANGLI-TEJAKULA & 3 unit & $52 \mathrm{~km}$ \\
\hline 5 & MENGWI -P.BAI & 16 unit & $53 \mathrm{~km}$ \\
\hline 6 & MENGWI-SANGSIT & 2 unit & $72 \mathrm{~km}$ \\
\hline 7 & GILIMANUK- KLK & 2 unit & $142 \mathrm{~km}$ \\
\hline 8 & BATUBULAN-AMLAPURA & 8 unit & $59 \mathrm{~km}$ \\
\hline & Jumlah Total & 187 unit & \\
\hline
\end{tabular}

Survey wawancara masyarakat dalam menggunakan moda angkutan pada Kawasan SARBAGITA dengan jumlah penduduk 2.128.580 Jiwa sampel yang di diambil merupakan:

Untuk nilai e $95 \%$ atau sig $=0.05$

$$
n=\frac{N}{1+N e^{2}}
$$

$n=\frac{2128580}{1+2128580 \times 0.05^{2}}=400$ sampel

Untuk nilai e $90 \%$ atau sig $=0.1$

$n=\frac{2128580}{1+2128580 \times 0.1^{2}}=100$ sampel

Maka diambil sampel responden nya sebanyak 130 responden yang mewakili penumpang. Setelah survey dilakukan kemudian data dianalisis untuk mengetahui jumlah variabel yang di dapat dan mempengaruhi masyarakat dalam melakukan aktifitas.
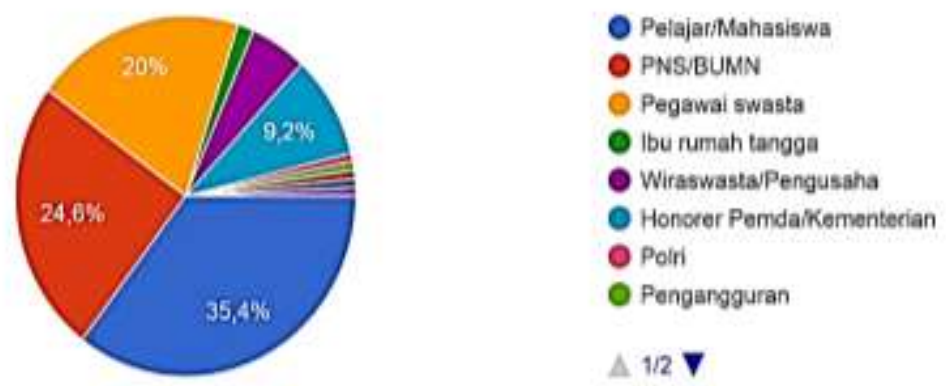

Gambar 1. Distribusi Jenis Pekerjaan Responden

Dari hasil survey responden karakterisik kepemilikan kendaraan pribadi antara roda 4 dan roda 2 masih sangat tinggi yang dimiliki oleh masyarakat SARBAGITA didistribusikan seperti pada gambar berikut.
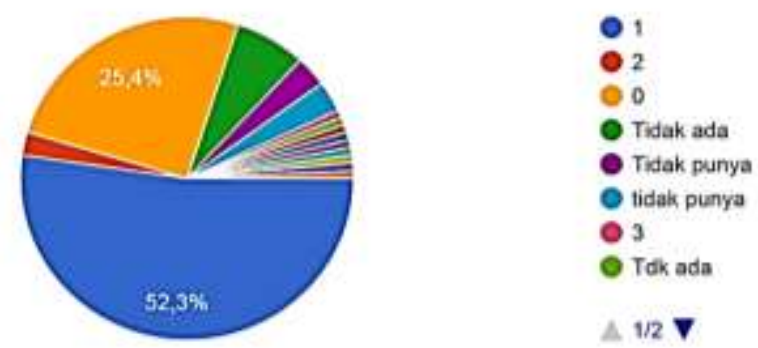


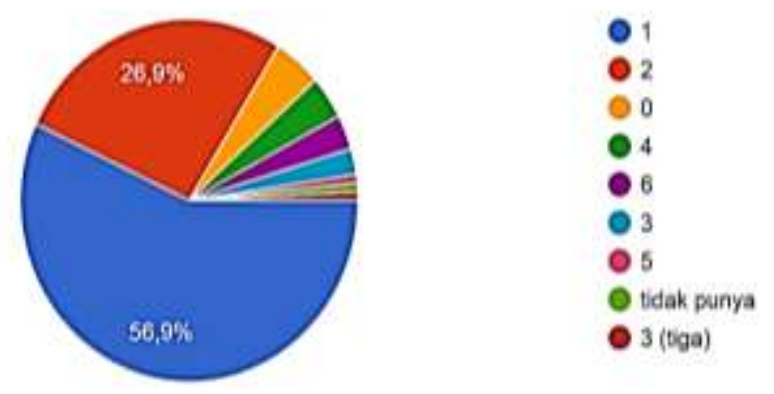

Gambar 2. Distribusi Jumlah Kepemilikan Kendaraan Bermotor

Jenis dan Jumlah Angkutan Umum

Angkutan umum masal adalah jasa angkutan yang memiliki trayek dan jadwal tetap, seperti bus dan kereta api. Jenis angkutan ini bukan melayani permintaan melainkan menyediakan layanan tetap, baik jadwal, tarif maupun lintasannya. Masing - masing mempunyai pola layanan dan kebutuhan yang berbeda. Oleh karena itu, keduanya dapat berfungsi secara bersama - sama di sebuah kota.

Menurut data yang didapatkan dari badan pusat statistic provinsi Bali dalam provinsi Bali dalam angka didapatkan grafik seperti pada gambar berikut:

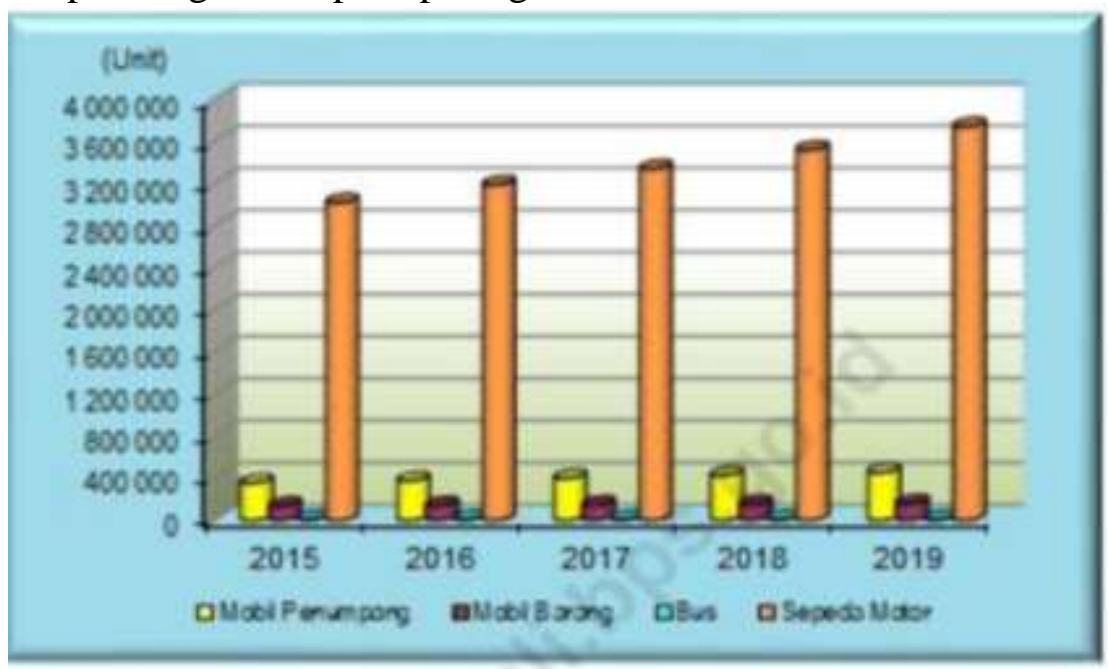

Gambar 3. Grafik Jumlah kendaraan bermotor di Bali dari tahun 2015-2019 Sumber: BPS Provinsi Bali

Dari grafik diatas bisa dilihat jumlah kendaraan sepeda motor di provinsi Bali dari tahun ke tahun meningkat dan jumlahnya terbanyak dari kendaraan bermotor lainya. Jika dilihat dari jumlah kendaraan mobil penumpang dari tahun 2015 - 2019 hampir tidak ada kenaikan dan perbandingan dengan kendaraan sepeda motor sangatlah besar.

Bus Trans Sarbagita dimaksudkan untuk menciptakan efisiensi perjalanan dan mampu menjangkau seluruh kawasan Sarbagita. Didukung oleh 11 Trayek Cabang dan 25 Trayek Ranting. Jumlah keseluruhan trayek adalah 53 trayek yang didasarkan pada kesiapan SaranaPrasarana, seperti kendaraan, halte, rambu termasuk Restrukturisasi Trayek pada setiap koridor. (Situs Resmi Dinas Perhubungan Pemerintah Provinsi Bali) Trayek Utama angkutan umum Trans Sarbagita ini terdiri dari:

1) Kota- GWK (Garuda Wisnu Kencana) PP

2) Batubulan-Nusa Dua PP Via Sentral Parkir Kuta 
3) Sanur-Petitenget PP Via Civic Center/ Nitimandala

4) Batubulan-Bandara Ngurah Rai PP Via Gatot Soebroto

5) Sanur- Ubud PP Via Kedewatan

6) Mengwi - Pelabuhan Benoa PP Via Kota

7) Mengwi - Bandara Ngr Rai PP Via Kerobokan

8) Sentral Parkir Kuta - Tanah Lot PP

9) Batubulan-Sentral Parkir Kuta PP Via Kota

10) Sanur-Nusa Dua PP Via Bandara Ngurah Rai

11) Sanur - Lebih PP Via Taman Safari

12) Sanur - Canggu PP Via Kota

13) Gianyar - Pesiapan PP Via Mengwi

14) Ubung - Sentral Parkir Kuta PP Via Buluh Indah

15) Mengwi - Batubulan PP Via Dalung

16) Tegal - Mambal PP

17) Mengwi - Batubulan PP Via Darmasaba

Trayek cabangnya yaitu: Tegal - Bandara Ngurah Rai. PP Via Sentral Parkir Kuta.

Adapun rute Bus Trans Sarbagita Trayek yang beroperasi saat ini ada 2 koridor :

Koridor 1 Terminal Batu Bulan -Nusa Dua

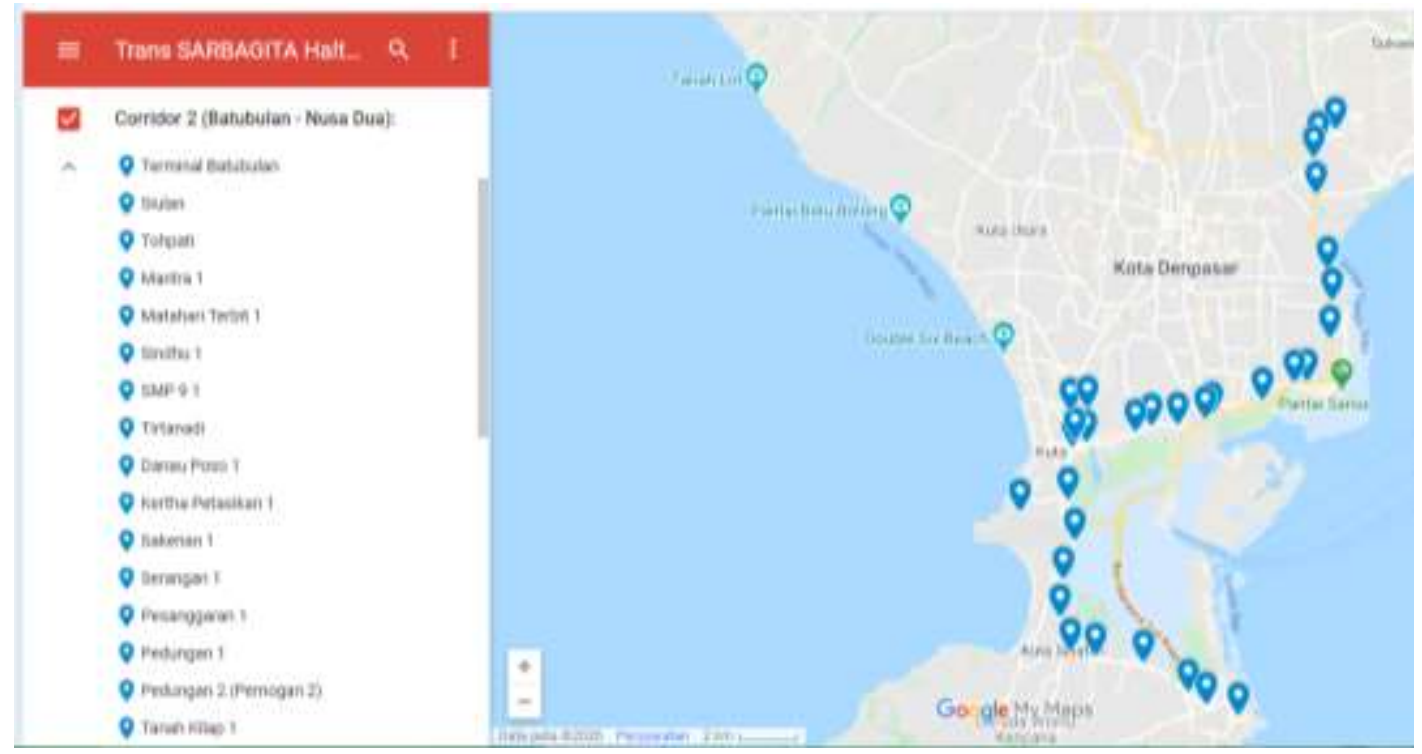

Gambar 4. Trayek Bus Sarbagita Batubulan - Nusa Dua

Koridor 2 Kota - GWK (Kota - Garuda Wisnu Kencana)

Bus Trans Sarbagita Trayek Kota - GWK merupakan bus sedang dengan kapasitas 35 orang. Bus Trans Sarbagita Trayek Kota - GWK ini mengoperasikan 8 (delapan) bus setiap harinya dan 2 (dua) bus sebagai cadangan. Tarif/Harga Bus Trans Sarbagita Trayek Kota - GWK ini adalah Rp 3.500,- untuk kalangan umum dan Rp 2.500,- untuk pelajar dengan menggunakan seragam atau dengan menunjukkan kartu tanda pelajar.

Untuk memaksimalkan layanan Trans Sarbagita, pemerintah kota Denpasar melalui Dinas Perhubungan Kota Denpasar, membuat Trayek Pengumpan (TP) atau dikenal dengan Feeder Trans Sarbagita dimana saat ini ada empat koridor, yaitu TP 01 (GOR Ngurah Rai - Renon), TP 02 (Matahari Terbit - Simpang Enam Teuku Umar), TP 03 (Simpang enam Teuku Umar - Pemogan - SMA 5 Denpasar), dan TP 04 (Suci - SMA 2 Denpasar - Sidakarya). Aksesibilitas Bus Trans Sarbagita Trayek Kota - GWK sangat terbantu dengan adanya trayek pengumpan ini. 


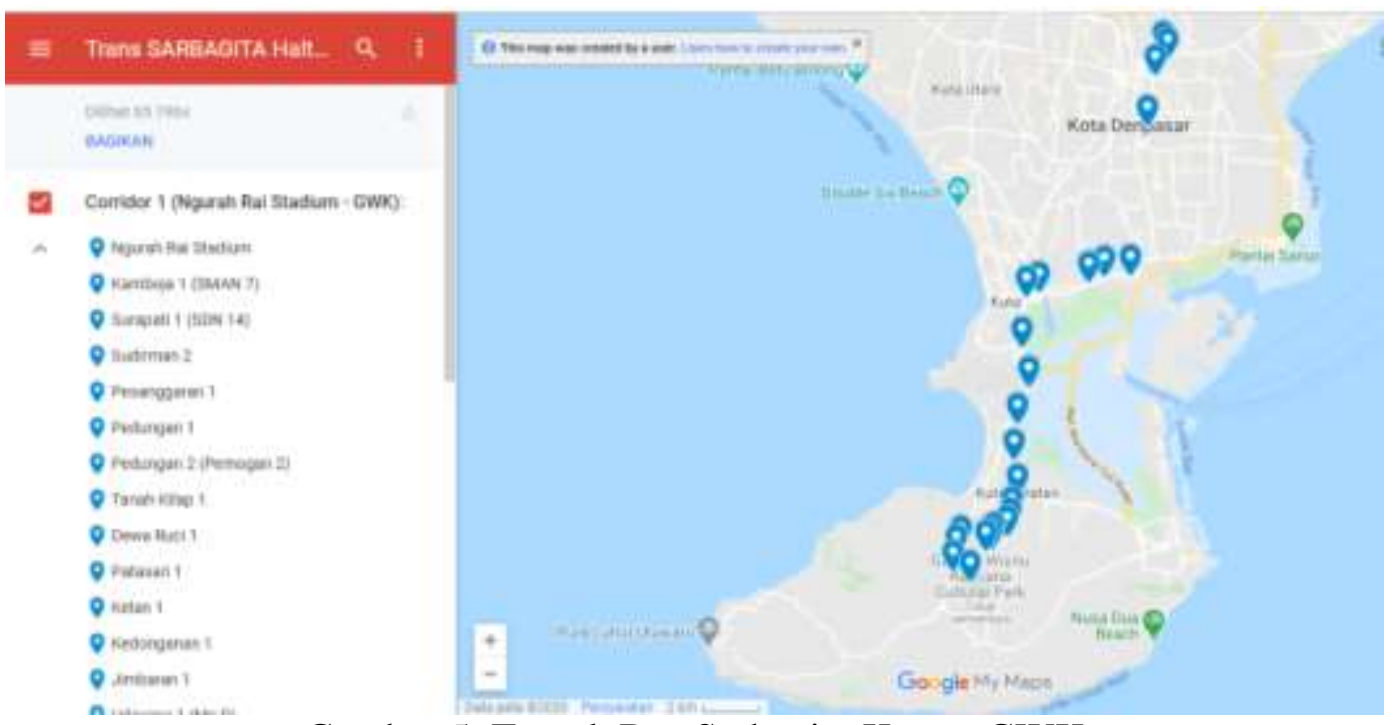

Gambar 5. Trayek Bus Sarbagita Kota - GWK

Teman Bus Merupakan program pengembangan angkutan massal perkotaan yang diinisiasi oleh Kementerian Perhubungan melaui Direktoral Jenderal Darat. Layanan Teman Bus sudah beroperasi dibeberapa Kota di Indonesia diantaranya Denpasar. Layanan Teman Bus memiliki standar pelayanan minimum yang dimiliki oleh operator diantanya : keselamatan, keamanan, kenyamanan, kesetaraan, keterjangkauan, dan keteraturan. Fasilitas Teman Bus dibekali peralatan IoT (Internet of Things) seperti CCTV, reader kartu non tunai, sensor penghitung jumlah penumpang, sensor alarm pada pengemudi untuk mendeteksi jika ada pelanggaran pada pengemudi, seperti mengantuk, merokok, tidak menggunakan seatbelt, keluar jalur/trayek maka akan berbunyi alarm dan informasi ke pusat command center secara real time. waktu headway yang ditentukan yaitu 10 menit.

Perencanaan layanan teman bus di Kawasan SARBAGITA rencananya ada 4 koridor :

1. Koridor 1 Terminal Pesiapan - Central Parkir Kuta Badung

2. Koridor 2 GOR Ngurah Rai - Bandara Ngurah Rai

3. Koridor 3 Pantai Matahari Terbit - Dalung

4. Koridor 4 Terminal Ubung - Sentral Parkir Monkey Forest

Mulai bulan Desember 2020 keempat koridor Teman Bus sudah mulai beroperasi.

Efektivitas dan Efisiensi Angkutan Umum Kawasan SARBAGITA

Menurut Agustini (2015), dari data BPS Provinsi Bali tahun 2015 jumlah kepemilikan kendaraan bermotor mencapai 2.749.164 unit. Dari jumlah kendaraan bermotor tersebut 1,9 juta unit berada di wilayah Kabupaten Badung dan Kota Denpasar. Pertumbukan jumlah kendaraan bermotor di Provinsi Bali tidak sebanding dengan panjang jalan yang ada di wilayah tersebut, yang hanya mencapai $7.504 \mathrm{~km}$ pada tahun 2011. Berdasarkan data dari survey yang telah dilakukan, dapat disimpulkan bahwa masyarakat di Provinsi Bali, Khususnya Kawasan Metropolitan SARBAGITA lebih memilih untuk menggunakan transportasi pribadi (contoh: sepeda motor dan mobil). Sebanyak 70,5\% responden memilih sepeda motor sebagai sarana transportasi, sebanyak $14,3 \%$ responden memilih menggunakan mobil dan hanya $8,6 \%$ yang memilih menggunakan angkutan umum. Dari data tersebut dapat disimpulkan para responden lebih mengedepankan waktu tempuh untuk memilih moda transportasi dan memilih sepeda motor karena dinilai lebih praktis dan efisien dari segi biaya yang dikeluarkan. Berikut data pemilihan moda transportasi berdasarkan survey penelitian dengan jumlah responden sebanyak 130 orang yang tinggal atau beraktivitas di kawasan Sarbagita: 


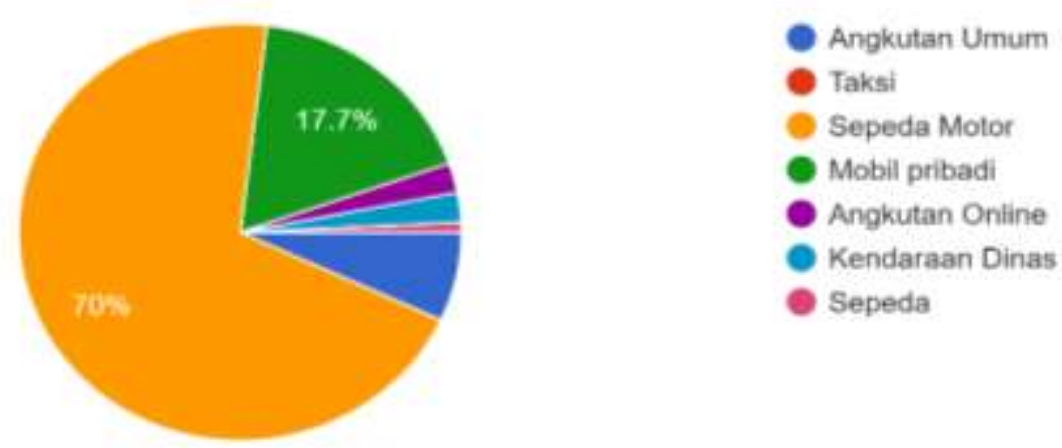

Gambar 6. Data Responden Pemilihan Moda Transportasi
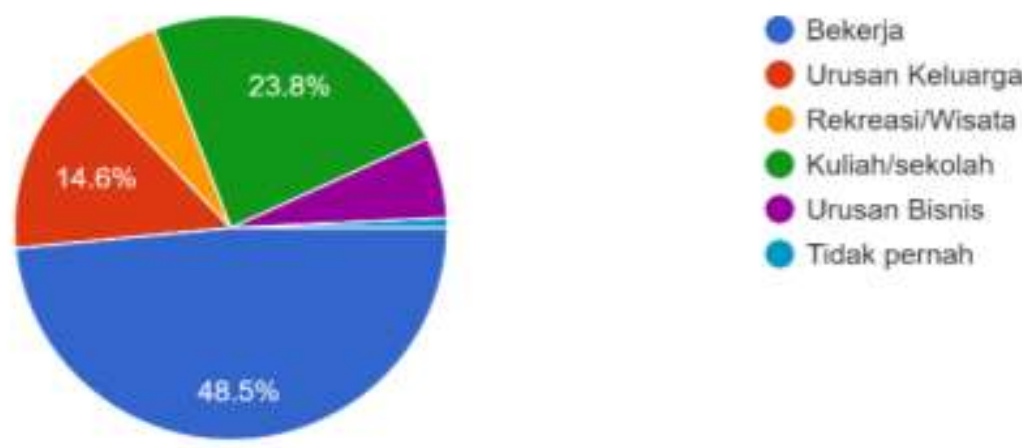

Gambar 7. Data Responden Maksud Perjalanan

Tujuan perjalanan yang dilakukan oleh 130 responden sebanyak 48,5\% untuk bekerja, 23,8\% untuk kuliah atau sekolah, dan 14,6\% untuk urusan keluarga.

Antusias masyarakat kawasan Metropolitan SARBAGITA terhadap keberadaan angkutan umum juga terbilang tinggi. Sebanyak $71,5 \%$ menjawab setuju menggunakan angkutan umum/massal yang terintegrasi. Pemerintah pusat dan daerah sudah berupaya untuk membangun sistem angkutan umum/massal contohnya: Teman Bus dan Trans SARBAGITA.
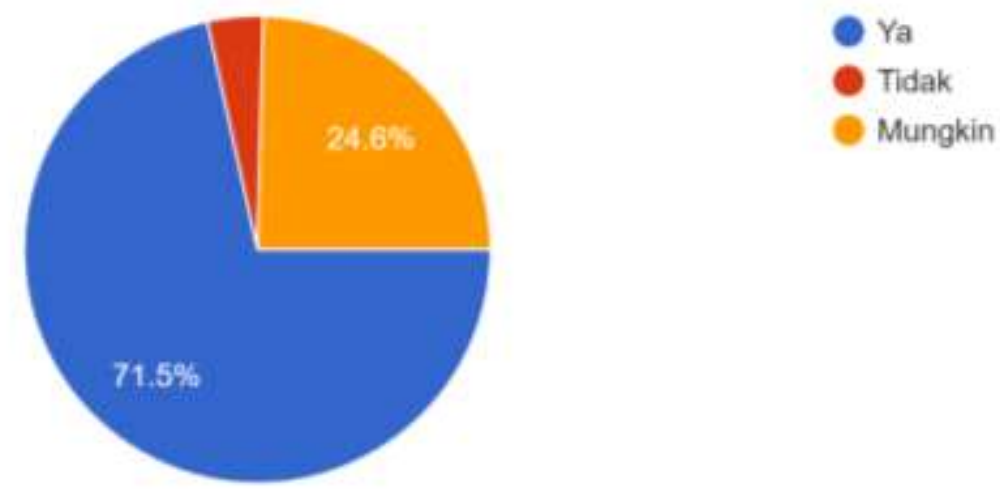

Gambar 8. Kemauan masyarakat untuk menggunakan angkutan umum yang terintegrasi

\section{SIMPULAN}

Pemerintah melalui program angkutan massal yaitu, Bus Trans Sarbagita dan Teman Bus mencoba untuk memperbanyak pilihan bagi masyarakat untuk bepergian. Permasalahan kemacetan mulai merambah ke kota-kota besar di Indonesia termasuk Kawasan Metropolitan Sarbagita, yang dikenal dengan sektor pariwisatanya. 
Pada 130 responden, untuk melakukan kegiatan sehari-hari sebanyak $70 \%$ menggunakan sepeda motor; $17,7 \%$ mobil pribadi; $6,9 \%$ angkutan umum; dan 2,3\% taksi online. Alasan para responden menggunakan moda transportasi yang mereka pilih adalah waktu tempuh lebih cepat sebanyak $49,2 \%$; keamanan dan kenyamanan $23,1 \%$; dan biaya yang lebih murah $20 \%$. Dari data tersebut dapat disimpulkan para responden lebih mengedepankan waktu tempuh untuk memilih moda transportasi dan memilih sepeda motor karena dinilai lebih praktis dan efisien dari segi biaya yang dikeluarkan.

\section{DAFTAR PUSTAKA}

Direktorat Jenderal Perhubungan Darat, 2015. Surat Keterangan Direktorat Jenderal Perhubungan Darat Tentang Pedoman Teknis Penyelenggaraan Angkutan Penumpang Umum di Wilayah Perkotaan Dalam Trayek Tetap Dan Teratur, Jakarta.

Nicolas Brotodewo. 2010. Penilaian Indikator Transportasi Berkelanjutan pada Kawasan Metropolitan di Indonesia, Jurnal Perencanaan Wilayah dan Kota, Vol. 21 (3), 165 182.

Peraturan Presiden Nomor 45 Tahun 2011 tentang Rencana Tata Ruang Denpasar, Badung, Gianyar, Tabanan.

Peraturan Presiden Nomor 51 Tahun 2014 tentang Perubahan Peraturan Presiden Nomor 45 Tahun 2011 tentang Rencana Tata Ruang Denpasar, Badung, Gianyar, dan Tabanan.

Putra Angga. 2016. studi evaluasi program Bus Trans Sarbagita Pemerintah Provinsi Bali, Kebijakan dan Manajemen Publik, Univeritas Airlangga, Surabaya.

Putrayasa Agus dan Maharani Sri. 2014. Efektifitas Bus Trans Sarbagita trayek Kota - GWK dalam mengurangi kemacetan di Kota Denpasar dan Kabupaten Badung, Soshum Jurnal Sosial dan Humaniora Vol 4, No 1 Maret, Politeknik Negeri Bali, Badung.

Soimun Ahmad, Widyastuti Hera. 2018. Analisis Probabilitas Perpindahan Moda Pengguna Kendaraan Pribadi (Sepeda Motor dan Mobil Ke Kereta Api Commuter Surabaya Sidoarjo Thesis, Teknik Sipil Institut Teknologi Sepuluh Nopember, Surabaya.

Vukan R. Vuchic. 1981. Urban Public Transportation. New Jersey. 